\title{
El desafío de mejorar la atención ambulatoria en pediatría
} Improving outpatient care in pediatrics: A challenge

Una parte importante de la atención primaria de la salud se brinda a través de los servicios ambulatorios, que llevan una larga y significativa tradición en la medicina. En gran medida, esos cuidados contribuyeron a instalar en la población los notables avances que se fueron produciendo en el Siglo XX. Se destacan aspectos tales como la protección de la salud, la motivación y recomendación de hábitos saludables y la prevención de diversas enfermedades; entre ellas las infecciosas mediante la implementación de medidas de higiene y estrategias específicas, donde sobresale la prescripción de vacunas, uno de los avances más trascendentes de la medicina.

Asimismo, más allá del esencial control en salud, la consulta permite sospechar o detectar enfermedades y tomar las medidas que correspondan.

Sin embargo, muchas cosas cambiaron en la profesión médica en los últimos 50 años. Existe un acuerdo unánime en señalar que los cambios no produjeron mejoras, ni para los médicos, ni para los pacientes. Las responsabilidades del médico cambiaron significativamente, en especial debido a los factores externos que rigen su accionar y que han sido influenciados por la creciente mercantilización del cuidado de la salud, los muy rápidos avances en medicina, la cada vez más apabullante información y la tecnología, que ha invadido intensamente la actividad médica.

Todo esto llevó a un deterioro progresivo de la atención primaria y ambulatoria que puede tener consecuencias imprevisibles. Un artículo reciente comienza con la siguiente frase: "El médico de atención primaria es una especie en rápida evolución y en el futuro podría convertirse en una especie en peligro de extinción". Esta premonición no parece exagerada, actualmente en EE. UU., más del 20\% de las consultas de atención primaria las realizan enfermeras profesionales, y este porcentaje sigue creciendo. En los párrafos iniciales del mencionado artículo, al referirse la autora al rol de los médicos de esta disciplina en el futuro cercano, surge una frase notable " ¿Se convertirán en socios o serán líderes de equipos multidisciplinarios que pasan más tiempo supervisando a los demás y menos interactuando con los pacientes?". ${ }^{1}$

Este último aspecto es esencial ya que los efectos negativos del deterioro perjudican principalmente la relación médico-paciente, cuyas consecuencias son deletéreas.
En gran medida, la aparición de los Sistemas Privados de Salud influyó marcadamente en la relación del médico con sus pacientes. La presión que ejercen ha motivado, entre varias otras cosas, que el tiempo de la consulta sea sumamente breve (unos 10 minutos); con esas condiciones es imposible brindar buena medicina. Al ser empresas con fines de lucro sus acciones están primariamente basadas en que la actividad sea rentable, y no en brindar un buen cuidado de la salud. Lamentablemente en nuestro país esto ha llevado al proletariado médico con un impacto mayor en los médicos de atención ambulatoria, donde la consulta tiene una paga absolutamente indigna. En todo este proceso de la medicina gerenciada por empresas con fines de lucro, hay potencialmente dos víctimas, los pacientes y los médicos.

En cuanto a la tecnología, debemos enfatizar que el problema no está primariamente en ella misma, que continuará desarrollándose cada vez más, sino en su aplicación innecesaria por los médicos. Esta conducta afecta a los pacientes, entre otras por la ansiedad e incertidumbre que les provoca, y asimismo, incrementa el financiamiento del cuidado de la salud. Se calcula que más de la mitad del exorbitante gasto en salud resulta de estudios auxiliares en la hospitalización y en la consulta ambulatoria, muchos de los cuales se solicitan sin ningún fundamento.

Respecto a la pediatría, la atención ambulatoria ha sido tradicionalmente uno de sus pilares más relevantes, al menos desde mediados del siglo 19. En la consulta se cultivaba la relación médico-paciente en un ambiente donde el pediatra y los padres hablaban y se escuchaban sin prisa. Esos encuentros contribuían a generar el cuidado del niño, no solo en lo relacionado con su salud, y eventualmente con su enfermedad, sino también en todo aquello que formaba parte de su evolución como persona, en el presente y en su futuro. Este concepto, sabiamente lo señaló el recordado Florencio Escardó. En su libro La Pediatría, Medicina del Hombre, decía "los pediatras siempre deben estar propensos a mirar más allá porque todo lo que hiciesen se iba a reflejar en la adultez del niño".

Asimismo, Gianantonio, nuestro siempre presente maestro, consideraba que ante la diversidad de los estratos sociales y culturales del niño, el pediatra debía tener una formación 
integral que articulara lo científico, psicológico, antropológico, social y comunicacional, y de esa forma iba a poder contribuir más eficazmente al desarrollo del niño y del adulto que será.

Actualmente, la atención ambulatoria continúa siendo uno de los pilares de la atención pediátrica, pero con el paso del tiempo, los notables cambios que he referido afectaron el ejercicio de nuestra actividad como pediatras y en cierta medida han motivado que disminuyeran o se perdieran varios de los principales atributos que teníamos.

Más allá de los negativos factores externos señalados, que no creo vayan a desaparecer, es propio y necesario que aceptemos las desviaciones o errores cada vez más frecuentes que se observan en la atención ambulatoria. Estos hechos ocurren en varias prácticas, aunque más notoriamente en la prescripción de medicamentos y estudios auxiliares; y en las recomendaciones en aspectos importantes: puericultura, nutrición, hábitos, prevención, etc.

Si nuevamente miramos hacia atrás, los pediatras fuimos siempre muy prudentes con las medicaciones y solo las indicábamos cuando era realmente necesario y por el tiempo más breve posible. La farmacoterapia segura y eficaz ha sido considerada como una de las estrategias clave en las mejoras de la salud del niño durante el siglo pasado. $^{2}$

Muchos pediatras, en especial los que tienen varios años de profesión, continúan respetando esa modalidad, que sin duda es beneficiosa y es la que debemos mantener.

Sin embargo, numerosas publicaciones muestran que en la pediatría se observa desde hace unos años un marcado e innecesario aumento en la indicación de medicamentos y en el uso de estudios auxiliares. Un estudio reciente describió la prescripción de drogas en una muestra de 133800 niños en Francia (90\% de la población pediátrica). En el período de un año, el 84\% de los niños recibió al menos un medicamento, que aumentó significativamente en los menores de 2 años, donde el $97 \%$ recibieron como mínimo una prescripción, porcentaje realmente escalofriante. ${ }^{3}$

Sobre la prescripción de antibióticos me referí en un editorial anterior; ${ }^{4}$ solo reitero que los datos de varios países señalan que más del $50 \%$ de los lactantes y niños con infecciones virales (tos, resfrío común, etc.) reciben antibióticos innecesariamente. Esta lamentable conducta no solo no representa ningún beneficio sino que produce daños potenciales y asimismo, incrementa la resistencia bacteriana.
Algo similar ocurre en el Síndrome de Déficit de Atención e Hiperactividad donde un número importante de niños y adolescentes reciben medicación no justificada.

Otro aspecto es la indicación de antipiréticos en niños con fiebre, donde parecería que la temperatura debe reducirse "a toda costa" aun cuando no sea elevada. Esta conducta se contrapone abiertamente al aceptado concepto que la fiebre es una respuesta natural y beneficiosa ante una infección y por lo tanto no deberíamos suprimirla. No hay evidencia alguna que la fiebre sea perjudicial, incluso en lactantes y niños que han tenido convulsiones febriles, tal como demuestra una revisión Cochrane. Tanto los padres como la mayoría de los pediatras le tienen miedo a la fiebre y eso puede explicar la inadecuada conducta que toman. ${ }^{5}$ Es probable que el miedo provenga de la ignorancia al suponer que la fiebre es dañina, pero también por inseguridad y temor a equivocarse en el diagnóstico.

Asimismo, es de destacar que la calidad global de la atención ambulatoria en pediatría está afectada. En una investigación se observó, entre otros varios aspectos, que apenas el $46 \%$ de los niños recibieron el cuidado adecuado y, lo que creo aún más grave, en el $50 \%$ de los niños evaluados a los dos años no se prescribió la inmunización completa. ${ }^{6}$

Como podemos ver, en estos tiempos realmente muy turbulentos y desfavorables para la profesión médica, los pediatras tenemos un enorme desafío para retomar el camino que nos lleve a brindar una atención ambulatoria lo más adecuada posible. Si lo logramos, muchísimos niños serán beneficiados.

\section{José M. Ceriani Cernadas} Editor

http:/ /dx.doi.org/10.5546/aap.2015.386

\section{REFERENCIAS}

1. Okie $S$. The evolving primary care physician. N Engl J Med 2012;366(20):1849-53.

2. Rieder M. Do we prescribe medicines rationally? Arch Dis Child 2015; Online first.

3. Bénard-Laribière $\mathrm{A}$, Jové $\mathrm{J}$, Lassalle $\mathrm{R}$, Robinson $\mathrm{P}$, et al. Drug use in French children: a population based reimbursement study. Arch Dis Child 2015; Online first.

4. Ceriani Cernadas JM. La indicación inadecuada e innecesaria de antibióticos en niños, un problema creciente. Arch Argent Pediatr 2015;113(1):2-3.

5. Richardson M, Purssell E. Who's afraid of fever? Arch Dis Child 2015; Online first.

6. Mangione-Smith R, DeCristofaro AH, Setodji CM, Keesey $\mathrm{J}$, et al. The quality of ambulatory care delivered to children in the United States. N Engl J Med 2007; 357(15):1515-23. 